\title{
Exploring the Ontological Status of the Race Concept as Perceived by Korean Medical Students
}

\author{
Jun-Ki Lee ${ }^{1}$, Sein Shin ${ }^{1}$, Hyo Hyun Yoo ${ }^{2 *}$ \\ ${ }^{1}$ Division of Science Education, Biology Major, Chonbuk National University, Jeonju, REPUBLIC OF KOREA \\ 2 Department of Medical Education, School of Medicine, Chonbuk National University, Jeonju, REPUBLIC OF KOREA
}

Received 5 September 2017 • Revised 11 December 2017 • Accepted 15 March 2018

\begin{abstract}
This study explored Korean medical students' perceptions of race from three perspectives: the definition of race, its biological reality, and the practical use of race information in medicine. Using three open-ended survey questions, we collected data from 506 Korean medical students. The data were analyzed through constant comparative analysis. We found diverse perceptions of race held by the students, which were similar to racial concepts that have emerged throughout the history of science. In addition, some students perceived race as a biological reality based on genetics and epidemiology. Lastly, $50.5 \%$ of students agreed to the use of the concept of race in the field of medicine for convenience, while the remainder disagreed with its use based on reasons such as racism, multi-culturalism, etc. Based on the results of this study, we suggest the development of an integrated educational program to increase students' understanding of race based on biology, culture, and ethics.
\end{abstract}

Keywords: biological reality, medical students, perception, race

\section{EXPLORING THE ONTOLOGICAL STATUS OF THE RACE CONCEPT AS PERCEIVED BY KOREAN MEDICAL STUDENTS}

When discussing race, it is true that public opinion can fail to keep up with the latest research findings (Bamshad, Wooding, Salisbury, \& Stephens, 2004; Heinz, Müller, Krach, Cabanis, \& Kluge, 2014; Keita et al., 2004; Lee, 2011). "Race" is a very long-standing concept in many areas such as medicine, biology, and anthropology. However, it is true that education and research on the topic has been neglected due to its uncomfortable history and unfortunate association with false beliefs or political aims such as social Darwinism or eugenics (Donovan, 2014).

Is the concept of race that we use both in our daily lives and in professional medicine a scientific concept? Is it a biological or medical concept? Is there any doubt about this? The debate over the issue of race has a very long history. Many recent studies have emphasized that human race is a social construct, like gender, and a misunderstanding of essentialism (Collins, 2004; Efstathiou, 2012; Schwartz, 2001). However, some scholars have repeatedly argued that the concept of race should be revived based on epidemiology studies or the convenience and practicality of patient care (Morris, 2011). In addition, the concept of silent racism has begun to resurface due to the emergence of genomics and pharmacogenetics (Collins, 2004; Jones, 2013). Some researchers in genomics, multinational pharmaceutical companies, and the field of pharmacogenomics have repeatedly argued that there is a scientific basis for the biological substance of race. Scholars believe that these claims are closely related to the illusion of a new market for race-specific medicines and bio-medical patents (Morris, 2011). Despite the perceived usefulness and convenience of the concept of race, its use in the process of patient management and research is problematic because neither is it a scientifically accurate nor useful concept. This is in fact a confusion arising from those who are trying to turn the issue into a question of values: what is right, wrong, and realistically convenient. The concept of race is a sensitive subject over which there is much debate concerning its ontological scientific realism (Hochman, 2014; Kaplan \& Winther, 2015; Winther \& Kaplan, 2013a, 2013b).

(C) 2018 by the authors; licensee Modestum Ltd., UK. This article is an open access article distributed under the terms and conditions of the Creative Commons Attribution License (http://creativecommons.org/licenses/by/4.0/).

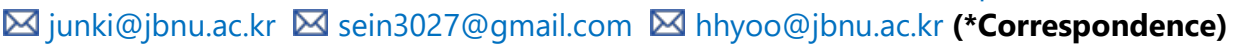




\section{Contribution of this paper to the literature}

- This study identified the various perceptions of race held by Korean medical students.

- In this study, it was confirmed that students' perceptions of race are closely related to their background knowledge on genetics, evolutionary science, and sociocultural knowledge.

- The various perception patterns of race identified in this study provide basic data for the development of SSI-style teaching and learning programs for medical students.

Why is it difficult to refer to concepts such as race in science and medicine? Why do racial issues complicate decision-making and reasoning, even though it is a question that is central to our nature as human beings? The reason is related to uncertainty about the concept or definition race. Where does this uncertainty come from? Perhaps the concept of race is subjective, unlike other concepts, because it has complex features that are scientific and sociological in nature (Efstathiou, 2012; Heinz et al., 2014). In general, in situations or problems involving these concepts, it is difficult to make subject-object distinctions because of the duality of exploring the objects of the outside world and oneself as the subject. In addition, problems related to human beings as subjects become naturally fused with other areas of our human cultural heritage. This domain is called "human science," and its problems and inferences are inclined to be complex (Hacking, 1995; Rose, 2012; Smith, 2005). In complex problem situations, concepts are often ill-defined or perhaps defined differently in many fields, and intertwined with the interpretations and interests of various actors. It is characterized by a large cognitive load that is nonlinear and chaotic in nature, which is sensitive to early concepts and perspectives, and opens the possibility of various positions and perspectives (Funke, 2010; Greiff, Krkovic, \& Nagy, 2013; Shin, Jonassen, \& McGee, 2003). Recently, science education has begun to pay attention to such real-world problems, and a representative example is the socio-scientific issues (SSI) approach. Race-related situations, like the real-world problems studied in the SSI approach, seem intuitively simple, but in fact they should be considered in terms of various points of view and domains; moreover, there may be complexity involved that is affected by the same initial sensitivity of the issue (Jacobson \& Wilensky, 2006).

Then, how do you perceive the concepts that cause complex situations such as race in the medical field, where you have to work directly with human beings and make professional judgments from time to time in complicated situations? How is the concept of race used in today's medical field and medical curriculum? The concept of race is considered to be an important statistical variable in epidemiologic studies, and it has been widely used in the labeling of gene samples in international clinical studies for medical research and drug development related to genetic diseases (Fullwilely, 2008). Through much of human history, we have never questioned the use of the concept of race. We have never been concerned about medical statistics, such as meta-analyses of collective research on gene samples or big data such as medical records based on racial categorizations. Many hospitals, including in the United States, require the patient's medical record card to contain racial information along with other personal information. In the registration process, the patient provides his own racial information based on his own racial self-awareness (Khan, 2012). This simple point further reveals the ambiguity in the examination of the concept of race. For example, how should a second-generation, African-American person state his or her identity? Do you have to check yourself as black or as a different race in the baseline questionnaire? If you do perceive yourself to be black, is this perception based on sociocultural identity or genetic ancestry? This is not a story that is confined to Europe or the US, but exists worldwide. For example, how do you express your racial identity if you were born in a multicultural family to a Korean mother and an English dad? It is difficult to answer this question using the current myths surrounding the concept of race. It is true that the concept of race, which is easy to encounter and use in everyday life, is difficult to define precisely, not only for the public, but also for medical professionals and biologists.

Today, many epidemiological and biomedical studies use racial concepts as the basis for patient classification and diagnosis, although this depends on the patient's own self-concept and self-perception (Alves, da Silva, Pinto, Toralles, \& Tavares-Neto, 2010; Khan, 2012). Thus, medical decision-making, communication, or diagnosis of patients may vary greatly depending on how doctors and bio-medical researchers perceive race. Bio-medical educators need to pay attention to medical students' perceptions of race because they will be physicians or medical researchers in the future and their perceptions can affect the practical diagnosis of numerous patients. Nevertheless, little is known regarding whether the epistemological and ontological status of the concept of race is a social construct or a scientific concept. Furthermore, it is feared that within a person's mental models, race may exist as a biosocial or founded concept, containing a mixture of sociocultural and scientific elements (Efstathiou, 2012). Recent studies in various countries have reported that attitudes and prescriptions for patients vary according to medical students' and physicians' perceptions of race (Alves et al., 2010; Bonham et al., 2009; Hoffman, Trawalter, Axt, \& Oliver, 2016; Josefson, 2000). From a long-term perspective, racial concepts can cause considerable problems in the medical community, and students who attend medical education institutions with little experience of sociocultural learning, such as Korea, may be less sensitive. In addition, it is known that Korean students (people) tend to learn 
as much through the sociocultural learning process as the formal educational process (Lee, Abd-El-Khalick, \& Choi, 2006). Korea has only recently begun changing into a multicultural society, and therefore, Korean students are rarely in contact with people of different races and ethnic backgrounds (Kim, 2015). Korean students, who live in a homogenous society, usually do not have many learning opportunities to explore the concept of race. However, due to the rapid increase in international marriages, Korea is now entering a multicultural era and the population of patients with diverse social and genetic backgrounds is growing. Therefore, it is necessary to examine whether changes in perception among medical professionals are accompanying this changing reality. Students currently enrolled in medical education institutes must formally receive racial and multicultural education because they completed their elementary and secondary education prior to the enactment of multicultural education (Kim \& Lim, 2016). Unlike in multicultural countries such as the United States, where people are exposed to multicultural learning from childhood, Korean medical students have no formal learning opportunities for these concepts until they enter medical school. Therefore, our question is "What kind of race concept do they form?" An exploration of Korean medical students' perceptions of race would provide insight for bio-medical researchers not only in Korea, but also in other countries currently undergoing the transition to a multicultural society.

Therefore, this study aims to explore more clearly the ontological status of the concept of race perceived by medical students as part of a foundational study for the development of SSI-style teaching and learning programs related to racial issues in the future curriculum of Korean medical education. In this study, we used three approaches to understand Korean medical students' perceptions of race. First, we investigated the types of ontological categories of the concept of race that Korean medical students perceived. Second, we explored the biological realities of the racial concepts perceived by the students. Third, the medical students' approval for the use of race in the field of medicine was examined.

\section{LITERATURE REVIEW}

\section{A Brief History of Race}

There is a difference between the concept of race and racism, but there is a strong connection between them. It is known from studies of sociology and evolutionary psychology that humans tend to group themselves into homogenous groups that share similar attributes while excluding those they perceive to be different (Hirschfeld, 1996; Kurzban, Tooby, \& Cosmides, 2001; Sumner, 1906).

There are various explanations for the origin of the concept of race (Heinz et al., 2014; Keevak, 2011), but it is generally believed to have originated in the 1480s with the Spanish Inquisition. At this time, laws of blood purity were enacted and the converts to Christianity had to prove their Christian faith. Furthermore, the concept of race began to be used as a means of persecuting Jews who had converted to Christianity in search of something that could not be changed by will and effort. However, existing Christians who were jealous of the converted Christians thought that because they were born Jews, they could not change even if they became Christian believers. From then on, Raza, which means "the seed of animals" in Spanish, began to be used as an insult to the Jews who converted to Christianity. Later, this changed to become the current English word "race" (Blum, 2010; Brückmann, Maetzky, \& Plümecke, 2009; Heinz et al., 2014; Lee, 2011; Wolf, 1994).

Racial discrimination was further intensified with the colonization that occurred under European imperialism. People living elsewhere had two theories to explain why their looks and behavior differed from Europeans (Keevak, 2011). First, there is the monogenism perspective. Monogenism states that all human beings are descended from a single gene type, but that "others" are somehow inferior or degenerated. Second, there is the polygenism perspective. The polygenism perspective is also called the Pre-Adamite hypothesis or Pre-Adamism. Polygenism states that humans stem from several different gene types. According to monogenism, although other races are "degenerated," they share their ancestry with Europeans and can be improved like Europeans if proper religious education is given. But according to polygenism, other races can never be "improved" through environmental factors (Keevak, 2011; Ludwig, 2014).

The concept of race has undergone a variety of changes since the fifteenth century. By the eighteenth century, the dominant racial perception of Europeans was mostly used to validate the superiority of whites and to distinguish between the inner group and outer group (Keevak, 2011; Lee, 2011). The typological concept of race advocated by scholars such as Linne, Kant, and Blumenbach also appeared at this time (Heinz et al., 2014; Keevak, 2011). In the eighteenth century, the slave trade was thriving in the time of European imperialism. The concept of race was used to justify racial discrimination and superiority (Heinz et al., 2014; Keevak, 2011). In the nineteenth and early twentieth centuries, "scientific racism" appeared. Scientific racism had been strengthened in the process of the imperial expansion of European society. Scientific racism combined biological characteristics such as genes with the sociocultural elements of religion, language, and geography to define race. The concept of race in this period was characterized by a strong biological or genetic determinism, and people perceived race as a kind of fate 
(Cartmill, 1999; Dar-Nimrod \& Heine, 2012). By the mid-twentieth century, however, advances in the field of biology convinced people that the classical concept of race has no scientific basis. Accordingly, the concept of race was regarded as meaningless, and finally, on November 27, 1978, UNESCO adopted the "Declaration on Race and Racial Prejudice" (Heinz et al., 2014; UNESCO, 1978). Based on this declaration, the concept of race was abandoned academically, socially, and politically. Since then, in the 2000s, genomics has emerged in biology communities, and with the successful completion of the Human Genome Project (HGP), a global project that transcended national boundaries, the concept of race entered a new phase. Francis Collins, head of the HGP, has warned of the resurgence of scientific racism through misuse of the results of the HGP, declaring that the concept of race so far is wrong and no longer relevant (Collins, 2004). Later, many scientists and societies began publishing articles on the notion that concept of race is incorrect. However, as biomedical research began gaining attention around 2010, the concept of race began to resurface, in particular, through the concept of "Race-Based Medicine," which has been used by pharmaceutical companies such as BiDil (Collier, 2012; Jones, 2013; Roberts, 2011). Anthropologists and sociologists have expressed serious concerns about this trend and the resurgence of outdated conceptions of race. In 2014, the American Association for the Advancement of Science (AAAS) held an annual general meeting on the issue of race, entitled "Neo-Racial Society in Post-Racial Societies." In this session, the researchers warned that the race-based or personalized medicine and education that is gaining momentum due to the recent academic trend of genomics will "bring risks to the future of science and society" (Yudell, Roberts, DeSalle, \& Tishkoff, 2016).

\section{Biological and Medical Issues Concerning the Concept of Race}

There is probably no one who can clearly answer, in one or two words, the question "What is race?" Race is a commonly used term and concept, but it has various definitions; moreover, it has a dual nature as both a natural science concept and a sociological concept (Heinz et al., 2014; Keita et al., 2004). In addition, the reason why the concept of race is so obscure is that our perceptions of race have evolved over time, as described in the previous section. The concept of race first began as a typological concept, but it changed into a statistical concept in the middle of the twentieth century. However, the human population is not an isolated Mendelian group, and many assert that there is no need to apply the concept of race to categorize human diversity (Morning, 2014; Shiao, Bode, Beyer, \& Selvig, 2012). Along with the emergence of single nucleotide polymorphism (SNP) techniques and pharmacogenetics, which are currently being used in biomedical research, the concept of race has begun to be used again (Paschou et al., 2007; Shiao et al., 2012). Montoya noted that by observing the research process of pharmacogenetics, scientists could commit serious errors in interpreting experimental results by projecting their sociocultural and historical assumptions and preconceptions onto a population of subjects (Haase, 2013; Montoya, 2011). For example, biological experiments have shown that the incidence of diabetes differs in various populations, but this is more due to sociohistorical factors than race. It is an error to attribute the occurrence of the disease to a specific gene. This is similar to the process through which Efstathiou (2012) described founded concepts being constructed, such as the concept of race. For this reason, the concept of race has been the subject of realistic debate in the field of philosophy of science (Andreasen, 1998; Biondi \& Rickards, 2002). In particular, ontological debates about whether race is a biologically real entity have occurred in studies in biology, philosophy, and anthropology (Andreasen, 1998; Bamshad et al., 2004; Kitcher, 2007; Templeton, 2013).

\section{The Present Study}

Modern medicine emphasizes the need for clinical genetics, and the boundaries between biology and medicine are becoming increasingly obscure (Lee, 2014; Ormond et al., 2011). Unlike students who are majoring in natural sciences and study whether race is a real concept, socially constructed, or a proxy used for convenience, medical students learn about race through statistical courses on diseases. In the process, the concept of race is introduced after the concept of popular and everyday race has already been transfigured into a founded concept of scientific soundness. Therefore, there is a large possibility that students will learn about race in an uncritical and perhaps even ambiguous manner, which they will later apply to their medical practices. It is therefore necessary for medical students to understand the sociohistorical complexities of the concept of race and to think critically about the subject. The purpose of this study is thus to explore the various ontologies and realistic positions of the perceptions of race held by Korean medical students and to utilize them as a basis for the development and integration of SSIbased instruction in the Korean medical curriculum.

\section{RESEARCH DESIGN AND METHODOLOGY}

\section{Participants}

The subjects of this study were 506 students enrolled in a Korean school of medicine. Seventy-one of the participants were in their second year of the undergraduate medical program, while the remaining 435 students 
were in graduate school. Of these 435 students, 110 students were in their first year, 97 were in their second year, 106 students were in their third year, and 122 students were in their fourth year of medical graduate school. Of the participants, 298 (58.9\%) were males and 207 (40.9\%) were females. All the participants signed an agreement to participate in the study, and were fully aware of the explanation given beforehand and participated in the study by voluntary consent. This study was conducted after preliminary review of the research plan of the institutional review board (IRB) of Chonbuk National University (approval number CBNU 2016-04-002-001).

\section{Data Collection and Analysis}

The questionnaire for data collection consisted of three parts. In the first part, we presented an open-ended question that asked the participants to describe the meaning of race. In the second part, a close-ended question asked whether race is a biological reality, and then an open-ended question asked the participants to describe the evidence or reasons for their thinking. In the third part, a selective question asked whether the concept of race was relevant or applicable to medicine, and finally another open-ended question asked the participants to describe the evidence or reasons for their thinking. We used the text data described and submitted by the students for our analysis. The content of the collected qualitative data (students' response text) was categorized in an inductive manner through a constant comparative analysis, and the types of race concepts recognized by the research participants were derived. Finally, we examined the distribution of concepts of race according to groups.

\section{Validity and Reliability}

To ensure the validity and reliability of the analyzed results, the triangulation method used in the qualitative research was used to ensure the validity and reliability of the results (Lincoln \& Guba, 1985). In this study, we tried to obtain a more integrated and contextual understanding by using the text of the students' responses, and from post-interviews conducted in some ambiguous cases. The first step categorizes the type through a constant comparative analysis that is repeated while reading the content of the transferred qualitative data. At this stage, the researchers, geneticists, medical educators, and biology educators have undergone several R \& D seminars to review the data after several consultations. The second step is to find the intersections of the categorized types. In this process, to understand race concept of the participants in the context, a representative case was extracted and typified. In this study, we constructed the results in this way and extracted contextual factors based on previous studies of students' race concepts. If there is an inconsistency in the analysis among the researchers, the related studies were further analyzed and then reanalyzed and compared again. The final inter-coder reliability (Cohen's Kappa) of this study was 0.89, which was higher than the lowest level (0.70) suggested by Fleiss (1981). In addition, the reliability of the analysis was improved through member-checking of the appropriateness of the researcher's analysis with participating students, major medical education specialists, medical school professors, and residents.

\section{RESULTS}

\section{The Ontological Status of the Race Concept}

Medical students have identified four distinct types of racial conceptions by inductively categorizing open textual materials freely describing the participant's concept of race. Of the total medical students who participated in the study, 85 students held typological concepts of race $(16.7 \%), 202$ students held biological concepts of race $(39.9 \%), 122$ students held sociocultural concepts of race $(24.1 \%)$, and 97 students held biosocial concepts of race $(19.1 \%)$. The following are examples of students' perceptions of race by type.

Typological concepts of race. Some of the medical students perceived race as a category that represents and distinguishes human diversity. This is the case for students LH, AJ, and YW listed below.

$$
\begin{aligned}
& \text { "The classification of people in terms of the color of skin" (Student LH). } \\
& \text { "It is a kind of person, and it varies according to what the criteria are" (Student AJ). } \\
& \text { "Classifying human beings based on observable features with the naked eye" (Student YW). }
\end{aligned}
$$

Student LH referred to the concept of race as a way of differentiating human beings according to their skin color, an idea that has existed for a long time. This is perhaps the most common conception of race, and at the same time, the concept applies intuitive distinctions to human diversity. Student YW also displayed a similar conception of race to Student LH. The notion of race, as described by Student YW, corresponds to the common concept of the directly observable differences in appearance, in other words, the way in which categories are set up for the manifestation of diversity in the human species. A similar conceptual recognition of race in terms of criteria for 
classifying human beings also appears in Student AJ's thinking. However, Student AJ does not only refer to the criteria of appearance such as skin color, but the ways in which people distinguish themselves.

Biological concepts of race. Among the various responses of the students, a biological viewpoint of race was held by several students. This is the case for students JS, KI, YC, and BS presented below.

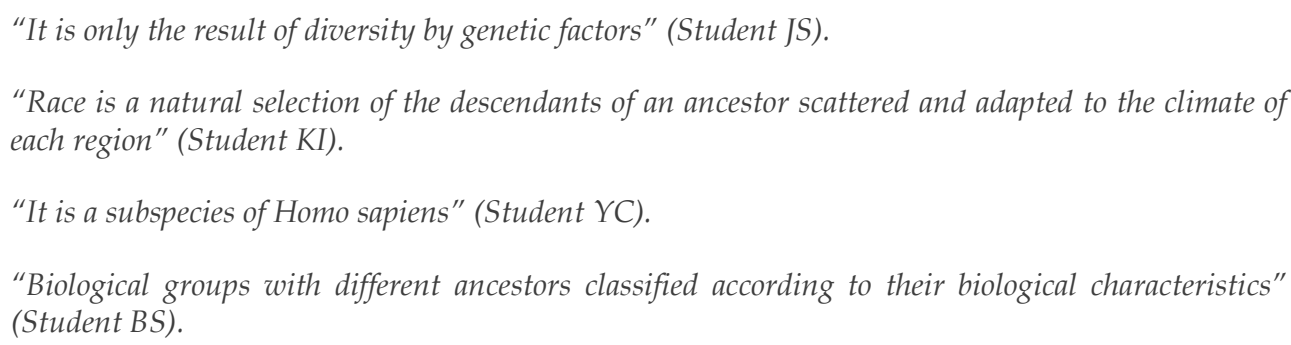

Student JS refers to "human diversity" and sees this diversity as being caused by genetic differences. The concept of race described by JS is based on biology, and in particular, on genetics. Student KI describes human diversity using common ancestry and origins concepts. Student KI's conception of race is also based on biological understanding; Darwinian evolutionary theory of adaptationism and natural selection was at the center of his perception. Meanwhile, Student YC referred to the concept of subspecies, which is usually used to refer to animals, recognizing race in terms of the biological diversity of humans. Student YC's conceptual understanding of race, which equates different races to subspecies, is based on the group genetic assumptions of Neo-Darwinism using isolated Mendelian assumptions for species differentiation. Student BS referred directly to biological characteristics. This perspective differs from the typological concept described by Student LH because Student BS understood race through the origins of human ancestors, not simply through observable characteristics. The perspective of Student BS is based on a systematic classification approach that is more concerned with the evolution of the human species than its present state.

The concept of race as a social construct. The medical students sometimes used social and cultural perspectives as important factors in representing racial concepts. The responses of students NS, KS, WJ, CH, PS, and MW presented below are examples of racial concepts as social constructs.

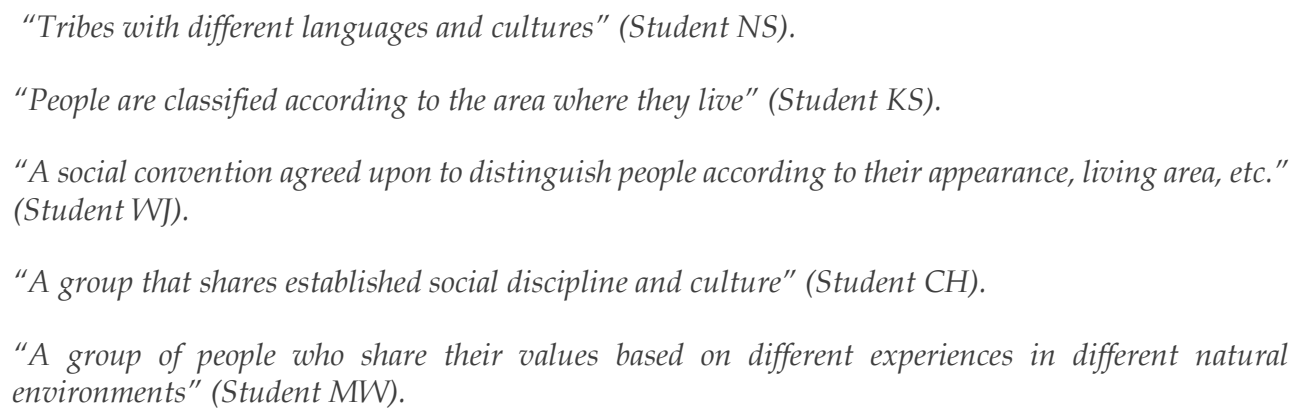

Student NS's concept of race was based on the diversity of human groups due to language and culture. Students KS and WJ also described race as a community that lived together in the same area. These perspectives can be viewed as assuming that the natural environment contributes to the creation of different behaviors in its inhabitants, such as "social agreement" (Student WJ) and "culture-sharing" (Student CH). A reference such as "a group of people sharing a value system" (Student MW) shows that the concept of race is viewed as a social construct created through the consensus of members of a given society.

Biosocial concept of race. Among the medical students' responses were those that represented the biosocial concept of race, a hybrid concept that combines biological and sociocultural elements. Students GW and SA's responses are representative of this viewpoint:

"A species is a collection of human beings who are capable of crossbreeding (e.g., intermarriage), and in the species, race consists of physical and cultural subdivisions" (Student GW).

"Race is dividing people through biological aspects (genes, skin color) and geographical and cultural aspects" (Student SA).

Student GW explained race by considering biological aspects and cultural elements, which is similar to the concept of group genetics held by Neo-Darwinists. This is a new type of concept in which biological and 
sociocultural concepts are recognized and integrated. The existence of such a mixed concept can be understood in terms of the cognitive resources recently proposed by diSessa, Gillespie, and Esterly (2004). In addition, Student SA considered both genes and cultural aspects in his/her concept of race.

\title{
Determining the Biological Reality of Race
}

The concept of race is a biological reality. After exploring the perceptions of race held by medical students, we analyzed their ideas concerning whether race is a biological reality or not. Among the students who answered that race is a real concept, a variety of reasons were given. The reason with the highest response rate of $30.2 \%(n=104)$ was attributed to differences in the incidence of disease among different races. Next, the concept recognition as biological reality through genetic or evolutionary (e.g., natural selection, adaptation) was 55.5\% ( $\mathrm{n}=192$ ). In addition, $14.3 \%(n=50)$ of the students stated that race was judged to be a realistic concept because of the evidence given in authoritative research studies. The following is a typical example of the explanation given by medical students who perceived race as a biological reality, students EJ, DC, JK, TH, and HH, as listed below.

\begin{abstract}
"It is true that the occurrence of disease varies according to race" (Student EJ).
"As I was studying the epidemiology of diseases, I noticed that genetic differences were caused by diseases that are specific to Asians or Westerners. These genetic differences show that race really exists" (Student DC).
\end{abstract}

"African-Americans or Jamaicans, for example, show excellent performances over other races in shortrange athletics, such as a 100-meter running" (Student JK).

"Culture, skin color, emotions, religion, and language have been gradually formed in the human group over tens of millions of years, and human color, strength, hair, appearance, and skeletons vary due to these influences" (Student TH).

"The concept of race should be considered biologically real. Because it is reasonable that scientists have published articles in scientific journals with the results of research using objective methodology" (Student HH).

Students EJ and DC found evidence for the concept of race through the difference in the prevalence of diseases according to race. Student DC mentioned that they learned this in epidemiology class, which is a major subject in medical school. There is much epidemiological evidence that there are differences in the occurrence of diseases according to ethnicity or race. Student JK, on the other hand, held similar views to the other two students quoted above, but mentioned a slightly different aspect. Student JK recognized the reality of the race concept through an old racial prejudice of the sports realm. It is biologically dominant or unhealthy from the time a particular race is born to a sport, such as athletics or swimming, due to differences in genetic traits, leading to ancestral races and ethnic groups (Condit et al., 2004; Kerr, 2010; McDonald, 2013). In addition, Student TH used both sociocultural and biological explanations to explain that the concept of race is based in reality. The conceptual recognition of this form of collective genetics and anthropology is identical to that of anthropology in the process of encountering and transforming genetics. It is characterized by the explanatory structure of the way in which locally isolated and separated human groups have formed their own cultures and this has in turn isolated gene pools. Finally, Student $\mathrm{HH}$ recognized the reality of the concept of race by relying on the authority of scientists and the articles they publish.

The concept of race is not a biological reality. Next, we examined the rationale of the medical students who answered that the concept of race is not real. First, 30.6\% $(n=49)$ of students gave the explanation of the impossibility of regional isolation, due to intermarriage, social change, and increased international interchange. Second, $29.4 \%(n=47)$ of the students cited all races as Homo sapiens because of phenotypic diversity, and that there are only genetically meaningless differences. Third, $29.4 \%(n=47)$ of the students' race concepts corresponded to abstract constructs such as social consensus, rather than concrete entities existing in nature. Fourth, $10.6 \%(n=17)$ of the students explained that that there is no counterpart to race in the natural world, and it is not a reality that can be observed. However, it can be used as a conceptual tool in medical research and development. In other words, the students explained that race is not a real entity, but merely a proxy based on medical convenience. Here are some typical examples of students' explanations, given by students CR, YB, and JO.

"Like many concepts in science today, the concept of race is nothing more than a consensus among ordinary people and modern scientists. Therefore, it is difficult to see that it actually exists in nature" (Student CR). 
"There may have been a distinctive biological factor that seemed racial in the past when interchanges between countries were difficult, but the concept of race through biological characteristics is no longer established in the present global age when gene flow is active. Thus, race does not exist" (Student YB).

"It is not a biological reality because it is a social concept that was created in the past by ambiguous research standards and methodologies" (Student JO).

Students CR and JO recognized race as a concept created through social consensus. In other words, according to these students, race is a social construct, so there is no real correspondence in the natural world: there is no biological reality and thus it is not a concrete concept. Furthermore, Student JO mentioned that race is an obsolete concept that is obscured by coarse methodology and does not exist. Student YB denied the existence of race and explained that it is difficult to use the concept of race in modern society due to continuous and active global gene flow, which is an idea based on a Neo-Darwinian biological concept.

\section{Possibilities for Using the Concept of Race in Medicine}

Acceptable uses of the concept of race in medicine. After confirming that the concept of race is biologically real, some medical students made an argument about the possibility of human classification based on race. Various reasons were given by the students for their approval of the use of race in medicine. The highest response of $39.8 \%$ $(n=102)$ was the convenience of its use as a patient classification system. The second highest response of $26.2 \%$ ( $n$ $=67)$ cited showing differences in the incidence of disease according to human diversity. Third, $14.9 \%(\mathrm{n}=38)$ of the students cited biological differences as the basis for use of the concept. Fourth, $19.1 \%(\mathrm{n}=49)$ of the students responded that they were aware of the reasons for using sociocultural differences. This is the case for students SR, $\mathrm{NG}$, DS, and $\mathrm{OH}$, as shown below.

"I do not think it is biologically real. However, I think that it will be practical and meaningful in the process of studying specific diseases to a specific race by medical means" (Student SR).

"There are different characteristics according to race, and I think it is not wrong to distinguish for convenience for treatment or research purposes" (Student NG).

"If it is possible that people could similarly distinguish between races in the information collecting process for convenience (especially statistics), I think it should be used. Because we could obtain social, economic, and medical statistics and distinguish (the differences), so the race concept could be used appropriately" (Student DS).

"There is the white race (Caucasian), black race (Negroid), yellow race (Mongoloid), Hispanic race, and they can be classified according to skin color, culture, language, and so on, so there is no problem with utilizing it medically" (Student $\mathrm{OH}$ ).

Student SR mentioned that race is a concept that is not biologically real. Nevertheless, Student SR agreed to the use of the concept of race in medicine because of its usefulness and convenience in research. The opinion was also held by Students NG and DS. Student NG recognized that racial distinction for the convenience for treatment or research purposes is not wrong. In addition, Student DS mentioned that it is possible to use race properly in the calculation of medical statistics, so it can be used appropriately. On the other hand, Student $\mathrm{OH}$, recognized race as a real concept and explained that since we have always classified humans based on sociocultural and biological characteristics, there is no problem in using the concept of race in medicine.

Unacceptable uses of the concept of race in medicine. The following are responses of the medical students' who answered that the concept of race cannot ethically be used for human classification in the field of medicine. Various reasons were given by the medical students for not agreeing to its use. First, $36.5 \%(n=93)$ of the students stated that the reason for its inappropriateness is that the human species consists of a single race: Homo sapiens. Second, $23.2 \%(n=52)$ answered that its use presented a potential risk due to the history of abuses of the concept of race. Third, $21.2 \%(n=55)$ answered that the genetic continuity of mankind is the basis for the inapplicability of the concept of race to the field of medicine. Fourth, $19.1 \%(n=50)$ of the students suggested that medical use of the concept of race is dangerous because it is a sociocultural concept and lacks objective and scientific definitions. Students RW, TS, HI, and HJ expressed these ideas in the comments listed below.

"There are no human beings with the same appearance in this world. By using the concept of race, which is a concept created by differences in appearance, to distinguish human beings, there is a risk that preconceived notions such as eugenics will occur even for convenience" (Student RW). 
"It should not be used because it is a traditional, unscientific notion that is made on the basis of incorrect standards and many things do not fit the modern situation" (Student TS).

"Because of the increase in multicultural families and the increase in international marriage and migration, it is difficult to apply old standards, as races are now mixed with others" (Student HI).

"The concept of race is one of the social codes that have changed with the times, and I think that the standard itself is different from individual to individual, thus, subjective and ambiguous" (Student HJ).

Student RW mentioned that the concept of race should not be used for human classification, even for convenience, based on the history of eugenics. In other words, the use of race-based ideas and practices can lead to racism and prejudice. Student TS was opposed to using the concept of race in medicine because it is a non-scientific concept that does not conform to modern standards. Rather, he/she stated, race is a traditional, constructed concept. Student HI expressed the same opinion. Student HI mentioned that we should not apply an old concept to a modern, global society where international marriage and immigration are increasing. In a similar way, Student $\mathrm{HJ}$ explained that the concept of race is a kind of social construct and norm, which is formed based on the specific situation of the times and period, and can no longer be used because the concept changes as the sociocultural situation changes.

\section{DISCUSSION}

The subject of race is one that must be delicately handled because of the risks associated with racism and prejudice in explaining human diversity. For this reason, the concept of race has been studied in both the biological education and medical education domains (Alves et al., 2010; Bonham et al., 2009; Donovan, 2014, 2015; Hoffman et al., 2016; Josefson, 2000). The concept of race is a basic concept in biology and medicine, and it is an essential concept that medical students should form through everyday experience in addition to formal education. In this study, we investigated the types of awareness of the concept of race held by Korean medical students. As a result, various concept types that appeared through the history of biology, medicine, and anthropology were identified through the students' various viewpoints. There was diversity in the concepts of race held by the students. The results of this study are as follows.

\section{The Concepts of Race Held by Korean Medical Students}

Every type of racial concept emerged during the developmental process of the history of science; these concepts were all expressed among the medical students surveyed for this study. From the data gathered through the student surveys, the conceptions of race as a biological reality, social construct, and biological-social concept were identified. This is consistent with the findings of previous studies in which students' conceptual development processes and intuitive preconceptions were similar to the conceptual changes observed in the history of science (McCloskey, Caramazza, \& Green, 1980). This means that, from a constructivist point of view, students construct various racial concepts before entering medical school, which they form due to various influences.

The participants of this study displayed various racial concept perceptions in addition to racial concepts from the scientific (biology) perspective. The typological view of race, which first appeared in Linne's Systema Naturae (1735), as well as in the works of Kant (1775), Blumenbach (1795), and finally with the 34 races of Garn (1971), remains prevalent today. Race, according to the typological view, is merely a tool or proxy concept that is useful for distinguishing among human beings (Heinz et al., 2014; Keevak, 2011). Barbujani (2005) also discussed this problem in the article "Human race: Classifying people vs. understanding diversity." In contrast, the concept of biological race appeared rapidly, and its understanding of race was based on evolutionary theory and genetics.

This ontological status of students' concepts of race is closely related to the assumption of population genetics and Neo-Darwinism that race can be regarded as an isolated Mendel group from other gene pools, which underlies the Hardy-Weinberg equilibrium (seven assumptions: organisms are diploid; only sexual reproduction occurs; generations are non-overlapping, mating is random; population size is infinitely large; allele frequencies are equal between the sexes; and there is no migration, mutation or selection) (Chen, 2010; Hardy, 1908). For example, in this study, the typological concept of race held by some students is like Mayr's (1942) view of race as an isolated Mendelian group similar to the subspecies concept in animal taxonomy. However, no group of human beings in the real world has ever been isolated as a Mendelian group, and now we know that the view of race as a biological subspecies is wrong. In addition, as in the case of Student GW, the concept of biological species was formed on the basis of the possibility of mating, and the concept of race was constructed on the basis of the biological species concept. In this case, the student was thinking about how social phenomena such as international marriage and intercontinental migration affect the isolation of gene pools. However, when there is a lack of population genetics 
and evolutionary prior knowledge, such as the gene pool concept, students' conceptions of race do not transcend the nineteenth century typological race concept of modern genetics. These examples can be easily found in the history of science. Neo-Darwinian researchers, such as Mayr, Simpson, and Dobzhansky have suggested that the concept of race is based on geographically isolated Mendel populations, considering the biogeographic point of view and the concept of subspecies of the human species (Homo sapiens) (Ganett, 2013). This was a statistical group concept. Scientists such as Dobzhansky (1951a, b) did not give up the past typological concepts of race, even when the main concern of the researchers was not the classification of mankind, but its origins. His attitude led to the emergence of a new, transfigured, founded concept that incorporates genetic grounds into the existing folk or ordinary race concept.

Even in 1972, a genetic study of the human race of fifteen different "race" populations by Lewontin (1972) found that there were more variations within the racial groups than among them; this seemed to prove that the typological race concept, which had been used since the nineteenth century, was biologically meaningless. However, the concept of race-especially the typological race concept-was not easily discarded and has been persistently resurrected, like the zombie of human history (Ludwig, 2014). This is similar to how the impetus and phlogiston theories did not disappear for a long time in the history of science. Therefore, the concept of stereotypical ethnicity is often referred to as modern phlogiston (Ludwig, 2014; Montague, 1970).

The conceptual learning process of medical students can be likened to the process of conceptual change in the history of science (McCloskey et al., 1980). Even though students have learned a new concept, the ontological shifting of the concept may not be complete. For example, when the student uses the new concept, he/she may feel conflicted over the inconsistency in the ontological status of the new learned concept and the pre-existing concept, perhaps eventually resorting back to the more familiar concept. This is because the integration of the ontological status of the concepts within the cognitive structure of the student is not accomplished, as if two concepts seem to coexist (Chi, 1992; Chi, Slotta, \& De Leeuw, 1994). As a good example, Reiner, Slotta, Chi, and Resnick (2000) suggested in their study that students should explain why they should keep the refrigerator door closed. Even though students had already learned the concept of heat, they could not explain the concept of thermal equilibrium. Rather, they explained that they had to prevent the cold air in the refrigerator from escaping, which resembles the caloric theory of heat. In this sense, the concept of race is difficult to maintain in the students' mental models. Such widespread and persistent concepts such as race are likely to cause conceptual alterations while remaining alive and attaching to other evidence; thus, ontological shifting is not certain (Efstathiou, 2012).

Although genetics education is essential, it has traditionally been treated only as a pre-admission course or as part of a foundation course in medical curricula. However, since modern medicine is entering the age of clinical genetics, the importance of genetics in medical education has been emphasized (Bonham et al., 2009; Chen et al., 2014; Choi, 2014).

Therefore, medical students can play a critical role in shaping the concept of race if they learn the basics of evolution and genetics. In the sociocultural definition of race, as in the studies of Cavalli-Sforza (2001, 2005), the sharing of culture and language is important. Finally, the biosocial definition of race, biology, and sociocultural factors are both taken into account. This altered synthesis concept is often found in ad hoc hypothesis fallacy, when science is used to achieve social goals; this, however, poses the risk of scientific racism or a return to eugenics (Biondi \& Rickards, 2002; Gould, 1981).

\section{Korean Medical Students' Perceptions of the Biological Reality of Race}

In this study, some of the medical students referred to pharmacogenetics, which is the study genetic differences in responses and reactions to pharmaceutical drug, and physical anthropological explanations to explain the concept of race as scientific or biological in origin. When they did not recognize the reality of the concept of race, many used explanations based on social constructivism. Constructivists often view scientific truths as beliefs shared by scientists. The constructivist view of race held by medical students suggests that racial phenomena are widespread in the field of medicine because the concept is used for classification and organizational purposes, rather than being encountered in natural science or biology. In addition, medical students may be prone to biogenomic cluster/racial realist perspectives because they are exposed to biomedical approaches within the curriculum and through ethics classes (Kaplan \& Winther, 2015; Winther \& Kaplan, 2013a). Particularly in epidemiology class, the students learn history and statistical data about the incidence and spread of various diseases. In this way, the students often learn about the concept of race in combination with various specific cases. One example is the case of students EJ and DC who claimed the biological reality of the concept of by explaining that the rates of specific diseases differ according to race. This can be seen as a stochastic and clustering type of racial awareness that relies on statistics such as the incidence of prostate cancer, which is higher in black men than white men (Jorde \& Wooding, 2004; Tsodikov et al., 2017). 
As many previous studies point out, race is not a scientific fact but a social construct (Biondi \& Rickards, 2002; Collins, 2004; Efstathiou, 2012; Schwartz, 2001). However, many of the medical students responded that race is a biological reality by citing various statistics showing different rates of disease among different genetic groups. However, the characteristics of various human skin colors can be attributed to the expression of pigment proteins. The central dogma is the logic that all apparent phenotypes are under the control of genes. Therefore, it can be inferred that if a specific disease caused by a deficiency or overexpression of a protein also differs by race, it shows that there are differences in genes. However, there is a problem with this genetic determinism or inference based on biological determinism. Based on the central principle, a misconception about race is formed in the process of thinking that all phenotypic differences must correspond to differences in genotypes (Dar-Nimrod \& Heine, 2012; Hyun, 2014; Youn \& Seo, 2014). It is a simple one-to-one correspondence to the probable difference in the appearance of the disease, and it starts to identify it as an independent isolated Mendel group. In the end, it appears to be a biological reality. This is similar to substance-based misconceptions in the physical science (Reiner et al., 2000).

Recent studies have shown that racial awareness is a serious problem affecting medical prescriptions (Bonham et al., 2009; Hoffman et al., 2016; Josefson, 2000). Hoffman et al. (2016) conducted a survey of 222 white medical students and residents using true and false statements about the biological differences between blacks and whites. According to the survey, $40 \%$ of first- and second-year medical students said that the statement "The skin of a black person is thicker than a white person" was true. About $25 \%$ of residents also thought that black skin was thicker. The students misunderstood many scientific facts about race. Half of the respondents answered that the statement "Whites are less likely to have heart disease than black people" was true. Racial biases and misconceptions have also been shown to affect physicians' prescription practices for patients. After giving medical records of white and black patients to the participants, the researchers asked about the patient's pain level and how to treat it. Ten experienced physicians who had not received any information about race were asked to examine the participants' suggested treatments. It was found that the treatments suggested by participants with more false beliefs about racial physical characteristics were more inaccurate. In addition, Josefson (2000) found that, because of the false belief that blacks are more tolerant of pain, in the emergency room of an Atlanta area hospital in the United States, whites $(74 \%)$ were more likely to be prescribed analgesics than blacks $(50 \%)$.

Therefore, for medical students to become competent doctors and make accurate medical judgments, a balanced and accurate education on the concept of race is needed. Currently, medical curricula often only teach race during statistical examinations of disease. It is important to note that typological or biological conceptions of race can be formed within students' cognitive structures through their association with central dogma, the basic principle of biology. For this, studying genetic phenomenon such as pleiotropy requires a curriculum that teaches not only the one-to-one correspondence between genotype and phenotype, but also the complex process. In addition, an integrated curriculum using an SSI-based instructional approach is needed to teach students that the concept of race is a sociocultural construct and should not affect medical decision-making.

\section{Korean medical students' perceptions of the use of race in medicine}

Third, we investigated the student perceptions of the possibility of using the concept of race in medicine. Recently, epidemiological journals have debated the issue of using race as a variable and on the grounds of causality issues (Bell, Adair, \& Popkin, 2004; Senior \& Bhopal, 1994; Shim, 2002). This is a very important variable in medical decision-making, for example, when developing a questionnaire for medical research, such as for epidemiological studies, when there is no clear consensus about the operational definition of a variable, or when the subject is in an ambiguous situation. In this case, even if studies have been conducted, statistical reasoning and medical decisionmaking may be difficult (Morning, 2014, Root, 2003; Shiao et al., 2012). In the case of the concept of race, the patient's reference point for their identity may be different. It is true that there is artificiality like the upper category, which is made for the convenience of classification rather than based on scientific substance that can be measured and proved. On the other hand, even if patients talk about their racial characteristics or the physician distinguishes them through observation, it is eventually subject to theory-dependent subjective judgments, so it is classified within the framework of interpretation of the concept of race. However, we are now relying on this method to create base data for decision-making for objective generalizations (Lin \& Kelsey, 2000).

As described above, race as a variable in patient background searches is an essential item in hospitals in every country, and both doctors and biomedical researchers consider it important (Alves et al., 2010; Lin \& Kelsey, 2000). Thus, the results of analyses collected and studied in this way also lose statistical, psychological, biological, and medical validity and reliability.

According to the results of this study, students were allowed to use the concept of race as a justification for the pragmatic purpose of studying patients and the convenience of gathering information. This means that it does not matter whether the race concept is a scientific (biological) concept or a social construct, or whether it even exists. Student SR, for example, stated that race is not a biological concept, but it can be used for its ease and practicality 
in the field of medicine. This is a concerning result, as it is similar to the logic of the typological race concept, which has been used since its inception to distinguish and categorize people. It also means that medical students, the doctors of the future, may use false concepts or fictional categorizations for pragmatic purposes or practical convenience. The concept of race has been used conventionally throughout the history of medicine until the present day, mostly for the purpose of group classification and without scientific basis or reality.

Since the Human Genome Project, biomedical researchers have focused on "race-based medicine" or "personalized medicine," and the boundary between pure biology and biomedical research, such as genetics and evolutionary medicine, has become blurred and fused. Whitmarsh and Jones (2010) found that racial concepts are merely a proxy used to identify subjects. Nonetheless, modern society is developing and fusing the boundaries between biology, biotechnology, medicine, and biomedicine. Increasingly, information concerning human genetic diversity is being used for commercial purposes. This recent environment has made it more difficult for students to establish clear concepts of race.

In past medical curricula, basic concepts taught in foundational courses were considered to have little to do with practice, for example, clinical care or therapy. Therefore, it has been pointed out that there is a serious lack of genetic literacy among physicians active in clinical practice and medical students prior to graduation. According to previous studies (Donovan, 2014, 2015; Ko, Choi, \& Lee, 2015), it has been reported that the recognition of basic concepts such as race, unlike their examination in the classroom using a SSI approach, often takes the form of complicated problems that require a lot of legal and ethical considerations when confronted by medical practitioners. For example, the question of what defines "life" is a similar case to the question of race. The ontological positions and patterns of the concept of life that students form can be very diverse and can be developed through everyday life or embryology lessons. In the secondary biology curriculum or in college embryology lectures, it is only necessary to learn and memorize factual information rather than critically examine the issue. However, how one defines life will determine what decisions they will make regarding euthanasia and abortion (Ju \& Lee, 2013; Ko et al., 2015; Yoo, Lee, \& Shin, 2017). For example, in the case of a student who the forms the opinion that a life begins from the fertilization stage where the sperm and the egg meet, even the use of the morningafter pill, a powerful estrogen preparation, would be considered as a kind of abortion and thus wrong. However, for students who perceive that neural tube formation or post-brain development signal the beginning of an independent life form, or for those who determine that independent life begins post-partum, decisions regarding abortion will be different. Life is considered to be the most central concept of biology and medicine, but in addition to scientific interpretation, diverse concepts exist together with sociocultural notions, forming religious and legal interpretations (Choi, 2011; Federspil \& Sicolo, 1994; Son, 2010; Yoo et al., 2017). Race also corresponds to this concept. Students who will be employed in professional occupations such as medicine need to be accustomed to the fact that knowledge can be used to serve various interests and perspectives.

In addition, most medical schools do not teach about the origin, history, and handling of race concepts through regular medical education curricula, even though race is a basic information item, regardless of whether it is a biological reality or not. Therefore, there is a risk of accepting this concept for fragmentary reasons, such as clinical usefulness, without knowing its history. The problem of the concept of race is similar to the problem of the perception of gender. To make medical judgments related to sexuality, endocrine physiology such as sex hormones is also needed, but in addition to sex, which is a biological concept, an understanding of gender is also necessary for doctors (Gould, 1981; Worthman, 1995).

In light of the above observations, should the concept of race be integrated into formal medical education in Korea? Race is a word that is used in both everyday life and in the field of medicine. It was a concept created for ease of understanding and remains for that very reason. It is a so-called modern phlogiston (Ludwig, 2014; Montague, 1970) of biology and medical education. Furthermore, the concept of race is used in medicine in a much wider range of ways than commonly thought, ranging from measurement, diagnosis, prescription, and even the definition of basic illness. But the ambiguity of the concept has not improved, considering that the concept of race remains deeply entrenched in every facet of the field of medicine (Goodman, 2000). However, despite its ubiquity, few people are aware of what the concept of race means or can explain it. As the results of this study confirm, even medical students are unsure of its meaning and explain the concept in various ways.

Therefore, if students do not have the opportunity to critically examine the concept of race during their formal education, they are more likely to use the concept intuitively (and thus, likely incorrectly) in medical decisionmaking and research. Therefore, it is necessary to implement an educational course on race for medical students. It is known that racism can occur in a person who has not formed a clear understanding of the concept; this can translate into false diagnoses and erroneous prescriptions in the case of doctors. 


\section{Study Limitations}

In this study, only one school of medical students in Korea participated. In the process of collecting open data on the concept of race, students were asked to describe their thoughts but not necessarily the scientific concept. However, a limitation of this approach was that the students were free to express their idea of the general concept neutrally. The promptness of the questionnaire induced quick responses from the respondents, however, according to spreading activation theory, people tend to associate meaning with the most dominant thoughts among the various perceptions that they have in the process of thinking about a certain concept (Anderson, 1983). It is thus the general tendency of people to express their most dominant thoughts in such a process. In addition, this study was not qualitative because statistical verification with a large sample of people was not performed; so there are limitations in generalizing the results. However, although the method used in the research is somewhat limited, the results are meaningful in that this study provides a more comprehensive understanding of the concepts of race held by medical students.

\section{Educational Implications}

One of the important goals of science education today is to develop the scientific literacy of students. According to this approach, utilization and practice are becoming more important than simply having knowledge. Thus, with the purpose in mind, science education curricula must focus more on societal issues. The problems of modern society are complicated and involve frequent conflicts among different values. Therefore, in science education, it is becoming more and more important to make scientific and ethical judgments about complex situations and to put them into practice. However, given that science is the product of human endeavors, and scientists are also human, most of the problems that modern science has to deal with are about ourselves. Learning to solve complex problems in modern society requires more complex elements other than simple scientific knowledge. Therefore, we must have the knowledge, attitude, and competence to make better decisions concerning our own problems.

Although Merton (1942) emphasized the value neutrality of science through CUDOS (a Mertonian norm meaning communalism, universalism, disinterestedness, and organized skepticism), in recent science education, SSI is a teaching strategy based on the assumption that scientific knowledge is not related to social problems (Fowler, Zeidler, \& Sadler, 2009; Macfarlane \& Cheng, 2008; Zeidler \& Nichols, 2009; Zeidler, Sadler, Simmons, \& Howes, 2005). In fact, the problems that arise in modern society, such as racial issues, cannot be value-neutral because human science is the problem of "ourselves," and decision-making on these issues requires not only simple scientific and technical information, but also social values, moral sensitivity, personal experience, and awareness of the nature of science (Lee et al., 2006; Smith, 2005; Yoon et al., 2014). The medical education curriculum is responsible for educating medical experts who must make direct decisions regarding human lives throughout their career. Education is thus critical because a doctor's scientific and social understanding of human-related issues affects medical decision-making and medical practice. In the case of issues such as gene therapy, "designer babies," abortion, and euthanasia, the best approach is through SSI-based instruction, PBL (Problem-based learning), and discussion classes in medical school.

The race concept is the modern phlogiston remaining in the field of medicine. To prevent the formation of incorrect knowledge or beliefs, medical students require better biology education. In 2017, the Korean medical graduate curriculum was overhauled for this purpose. In the existing medical school system, students from diverse undergraduate faculties were able to become doctors by enrolling in professional graduate schools. However, in the future, it is necessary to begin educating students directly after high school. There may be various changes in the Korean medical education system, but perhaps the biggest problem is basic science education that forms the foundation of medicine, especially biological education. As can be seen from this study, the concept of race is not taught in the formal Korean curriculum, in neither elementary nor secondary education, but the concept is deeply ingrained in the students' cognitive models. Students who will be physicians and responsible for human lives should not have an outdated and inappropriate conception of race that has already been abandoned scientifically. In addition, because the concept of race one holds forms the basis for one's attitudes and behaviors regarding race, if medical students hold outdated and inaccurate concepts, this can actually prove to be dangerous in Korea's transition to a multi-cultural society. Recently, the number of foreign residents in Korea has exceeded 2 million, accounting for $3.9 \%$ of the total population. They have various contexts for foreign workers, marriage immigrants, and foreign students. In addition, their country of origin has been diversified, and the proportion of multi-cultural families has also increased due to the increase in international marriages. Korean doctors now have more opportunities to meet patients with diverse cultural differences and racial/ethnic backgrounds than ever before in their daily lives. Unlike in the past, doctors in Korea often encounter race concepts and become confused in the process of charting patients or prescribing appropriate medicines in a routine medical setting.

Race is a subject that has been intricately intertwined with biology, as well as political and social issues. Therefore, changes in the curriculum are required for students to form scientifically accurate conceptions of race. 
In medical school, it is often the case that the concept of race is introduced as background information on statistical variables and individual identification in epidemiology subjects. This corresponds to the concept of race as a patient classification identifier based on practicality. To assist medical students in the formation and change of their conceptions of race, it is necessary to develop curriculum on race using a biological approach that draws on population genetics, neo-Darwinian evolution (modern synthesis), and epidemiology. For this purpose, it is necessary to introduce a variety of instructional approaches such as PBL or SSI-based discussion classes, in which the biological content of race is centered within the curricula of medical schools. Through a better educational approach, it is hoped that students will be able to rise above their own inherent, cognitive biases and biological essentialism.

\section{REFERENCES}

Alves C., da Silva, M. S. D., Pinto, L. M., Toralles, M. B. P., \& Tavares-Neto, J. (2010). Definition and use of the variable "race" by medical students in Salvador, Brazil. São Paulo Medical Journal, 128(4), 206-210. https:/ / doi.org/10.1590/S1516-31802010000400006

Anderson, J. R. (1983). A spreading activation theory of memory. Journal of Verbal Learning and Verbal Behavior, 22, 261-295. https:// doi.org/10.1016/S0022-5371(83)90201-3

Andreasen, R. O. (1998). A new perspective on the race debate. The British Journal of Philosophy of Science, 49, 199225. https://doi.org/10.1093/bjps/49.2.199

Bamshad, M., Wooding, S., Salisbury, B. A., \& Stephens, J. C. (2004). Deconstructing the relationship between genetics and race. Nature, 5, 598-608. https:/ / doi.org/10.1038/nrg1401

Barbujani, G. (2005). Human races: classifying people vs. understanding diversity. Current Genomics, 6, 215-226. https:// doi.org/10.2174/1389202054395973

Bell, A. C., Adair, L. S., \& Popkin, B. M. (2004). Understanding the role of mediating risk factors and proxy effects in the association between socio-economic status and untreated hypertension. Social Science $\mathcal{E}$ Medicine, 59, 275-283. https:/ / doi.org/10.1016/j.socscimed.2003.10.028

Biondi, G., \& Rickards, O. (2002). The scientific fallacy of the human biological concept of race. Mankind Quarterly, $42(4), 355-388$.

Blum, L. (2010). Racialized groups: The sociohistorical consensus. Monist, 93, $298-320$. https:/ / doi.org/10.5840/monist201093217

Blumenbach, J. F. (1795). De Generis Humani Varietate Nativa (5 $5^{\text {th }}$ ed.). Göttingen: Vandenhoeck. https://doi.org/10.5962/bhl.title.35972

Bonham, V. L, Seller, S. L., Gallagher, T. H., Frank, D., Odunlami, A. O., Price, E. G., \& Cooper, L. A. (2009). Physicians' attitudes towards race, genetics and clinical medicine. Genetic in Medicine, 11(4), 279-286. https:// doi.org/10.1097/GIM.0b013e318195aaf4

Brückmann, T., Maetzky, F., \& Plümecke, T. (2009). Rassifizierte gene: Zur aktualität biologischer rasse-konzepte in den neuen lebenswissenschaften. In AG gegen Rassismus in den Lebenswissenschaften (ed.), Gemachte differenz: Kontinuitäten biologischer rasse-konzepte (pp. 20-64). Münster: unrast-Verlag.

Cartmill, M. (1999). The status of the race concept in physical anthropology. American Anthropologist, 100(3), 651660. https:// doi.org/10.1525/aa.1998.100.3.651

Cavalli-Sforza, L. L. (2001) Genes, peoples, and languages. Berkeley, CA: University of California Press.

Cavalli-Sforza, L. L. (2005) The Human Genome Diversity Project: Past, present and future. Nature Reviews Genetics, 6, 334-340. https://doi.org/10.1038/nrg1596

Chen, J. J. (2010). The Hardy-Weinberg principle and its applications in modern population genetics. Frontiers in Biology, 5(4), 348-353. https:/ / doi.org/10.1007/s11515-010-0580-x

Chen, L., Goodson, P., Jung, E., Muenzenberger, A., Xu, L., Kwok, O., \& Li, M. (2014). Effectiveness of a web-based genomics training for health educators in Texas. Genetics in Medicine, 16(3), 271-278. https:/ / doi.org/10.1038/gim.2013.100

Chi, M. (1992). Conceptual change within and across ontological categories: Examples from learning and discovery in science. In R. Giere \& H. Feigl (Eds.), Cognitive models of science (pp. 129-186). Minnesota: University of Minnesota Press.

Chi, M. T. H., Slotta, J. D., \& De Leeuw, N. (1994). From things to processes: A theory of conceptual change for learning science concepts. Learning and Instruction, 4, 27-43. https:/ / doi.org/10.1016/0959-4752(94)90017-5 
Choi, H. K. (2014). Undergraduate nursing students' perceived knowledge and attitudes toward genetics and nursing competencies for genetics. Journal of Korean Biological Nursing Science, 16(2), 69-79. https:/ / doi.org/10.7586/jkbns.2014.16.2.69

Choi, K. (2011). Bioethics and 'bioethics and law': An academic identity and future of interdisciplinary bioethics in a pluralistic society. Ewha Law Journal, 17(1), 241-60.

Collier, R. (2012). A race-based detour to personalized medicine. Canadian Medical Association Journal, 184(7), E351E353. https://doi.org/10.1503/cmaj.109-4133

Collins, H. (2004). What we do and don't know about 'race,' 'ethnicity,' genetics and health at the dawn of the genome era. Nature Genetics, 36(11 Supplement), 13-15. https:/ / doi.org/10.1038/ng1436

Condit, C. M., Parrott, R. L. Harris, T. M., Lynch, J., \& Dubriwny T. (2004). The role of "genetics" in popular understandings of race in the United States. Public Understanding of Science, 13, 249-272. https:/ / doi.org/10.1177/0963662504045573

Dar-Nimrod, I., \& Heine, S. J. (2012), Genetic essentialism: On the deceptive determinism of DNA. Psychological Bulletin, 137(5), 800-818. https:/ / doi.org/10.1037/a0021860

diSessa, A. A., Gillespie, N. M., \& Esterly, J. B. (2004). Coherence versus fragmentation in the development of the concept of force. Cognitive Science, 28, 843-900. https://doi.org/10.1207/s15516709cog2806_1

Dobzhansky, T. (1951a). Genetics and the origin of species (3rd ed.). New York University of Columbia Press.

Dobzhansky, T. (1951b). Human diversity and adaptation. Cold Spring Harbor Symposia on Quantitative Biology, 15, 385-400. https:// doi.org/10.1101/SQB.1950.015.01.037

Donovan, B. M. (2014). Playing with fire? The implication of the hidden curriculum in school genetics on essentialist conceptions of race. Journal of Research in Science Teaching, 51(4), 462-496. https:/ / doi.org/10.1002/ tea.21138

Donovan, B. M. (2015). Reclaiming race as a topic of the U. S. biology text book curriculum. Science Education, 99(6), 1092-1117. https://doi.org/10.1002/sce.21173

Efstathiou, S. (2012). How ordinary race concepts get to be usable in biomedical science: An account of founded race concepts. Philosophy of Science, 79(5), 701-713. https:/ / doi.org/10.1086/667901

Federspil, G., \& Sicolo, N. (1994). The nature of life in the history of medical and philosophic thinking. American Journal of Nephrology, 14(4-6), 337-343. https:/ / doi.org/10.1159/000168745

Fleiss, L. (1981). Statistical methods $r$ rates and portion. New York: Wiley

Fowler, S. R., Zeidler, D. L., \& Sadler, T. D. (2009). Moral sensitivity in the context of socioscientific issues in high school science students. International Journal of Science Education, 31(2), 279-296. https:/ / doi.org/10.1080/09500690701787909

Fullwilely, D. (2008). Race and genetics: Attempts to define the relationship. Biosocieties, 2, $221-237$. https:/ / doi.org/10.1017/S1745855207005625

Funke, J. (2010). Complex problem solving: A case for complex cognition. Cognitive Processing, 11, $133-142$. https:// doi.org/10.1007/s10339-009-0345-0

Gannett, L. (2013). Theodosius Dobzhansky and the genetic race concept. Studies in History and Philosophy of Biological and Biomedical Science, 44(3), 250-261. https:/ / doi.org/10.1016/j.shpsc.2013.04.009

Garn, S. (1971). Human Races (3rd ed.). Springfield, IL: Charles C. Thomas.

Goodman, A. H. (2000). Why genes don't count (for racial differences in health). American Journal of Public Health, 90(11), 1699-1702. https:/ / doi.org/10.2105/ AJPH.90.11.1699

Gould, S. J. (1981). The mismeasure of man. New York: W. W. Norton \& Company.

Greiff, S., Krkovic, K., \& Nagy, G. (2013). The systematic variation of task characteristics facilitates the understanding of task difficulty: A cognitive diagnostic modeling approach to complex problem solving. Psychological Test and Assessment Modeling, 56(1), 83-103.

Haase, R. (2013). Michael J. Montoya, making the Mexican diabetic: Race, science, and the genetics of inequality. Social History of Medicine, 26(2), 305-306. https:/ / doi.org/10.1093/shm/hks121

Hacking, I. (1995). The looping effects of human kinds. In D. Sperber, D. Premack, \& A. J. Premack (Eds.), Causal cognition: A multidisciplinary debate (pp. 351-383 and pp. 384-394 ['Discussion']). Oxford: Clarendon.

Hardy, G. H. (1908). Mendelian proportions in a mixed population. Science, 28(706), 49-50. https://doi.org/10.1126/science.28.706.49

Heinz, A., Müller, D. J., Krach, S., Cabanis, M., \& Kluge, U. P. (2014). The uncanny return of the race concept. Frontiers in Human Neuroscience, 8(836), 1-10. https:/ / doi.org/10.3389/fnhum.2014.00836

Hirschfeld, L. A. (1996). Race in the making. Cambridge, MA: MIT Press. 
Hochman, A. (2014). Unnaturalised racial naturalism. Studies in History and Philosophy of Biological and Biomedical Sciences, 46, 79-87. https:/ / doi.org/10.1016/j.shpsc.2014.05.002

Hoffman, K. M., Trawalter, S., Axt, J. R., \& Oliver, M. N. (2016). Racial bias in pain assessment and treatment recommendations, and false beliefs about biological differences between blacks and whites. Proceedings of the National Academy of Sciences USA, 113(16), 4296-4301. https:/ / doi.org/10.1073/pnas.1516047113

Hyun, J. H. (2014). Changing methodologies and reshaping concepts in biodiversity science: A historical review of research on human genetic diversity. Korean Journal of Environmental Biology, 32(4), 413-425. https:/ / doi.org/10.11626/KJEB.2014.32.4.413

Jacobson, M. I., \& Wilensky, U. (2006). Complex systems in education: Scientific and educational importance and implications for the learning sciences. Journal of the Learning Science, 15(1), 11-34. https://doi.org/10.1207/s15327809j1s1501_4

Jones, D. S. (2013). How personalized medicine became genetic, and racial: Werner Kalow and the formations of pharmacogenetics. Journal of the History of Medicine and Allied Sciences, 68(1), 1-48. https://doi.org/10.1093/jhmas/jrr046

Jorde, L. B., \& Wooding, S. P. (2004). Genetic variation, classification and 'race'. Nature Genetics, 36(11), S28-S33. https://doi.org/10.1038/ng1435

Josefson, D. (2000). Pain relief in US emergency rooms is related to patients' race. British Medical Journal, 320(7228), 139.

Ju, I., \& Lee, H. (2013). Patterns of middle school students' value-judgement and decision-making on biotechnologyrelated socioscientific issues. Journal of the Korean Association for Science Education, 33(1), 79-93. https://doi.org/10.14697/jkase.2013.33.1.079

Kant, I. (1775). Von den verschiedenen Racen der Menschen. Königsberg.

Kaplan, J. M., \& Winther, R. G. (2015). Realism, antirealism, and conventionalism about race. Philosophy of Science, 81, 1039-1052. https:// doi.org/10.1086/678314

Keevak, M. (2011). Becoming yellow: A short history of racial thinking. Princeton, NJ: Princeton University Press. https:// doi.org/10.1515/9781400838608

Keita, S. O., Kittles, R. A., Royal, C. D., Bonney, G. E., Furbert-Harris, P., Dunston, G. M., \& Rotimi, C. N. (2004). Conceptualizing human variation. Nature Genetics, 36(11), S17-S20. https:/ / doi.org/10.1038/ng1455

Kerr, I. B. (2010). The myth of racial superiority in sports. The Hilltop Review, 4(1), 19-27.

Khan, J. (2012). Race in a bottle: The story of BiDil and racialized medicine in a post-genome age. New York: Columbia University Press. https:/ / doi.org/10.7312/kahn16298

Kim, K. H. (2015). Restructuring the discourses for a real multi-cultural society in South Korea. OMNES: The Journal of Multicultural Society, 5(2), 1-27. https:/ / doi.org/10.15685/omnes.2015.01.5.2.1

Kim, S. Y., \& Lim, M. (2016). A study on multicultural experience, multicultural perception, and multicultural selfefficacy of pre-service science teachers. Journal of Learner-Centered Curriculum and Instruction, 16(9), 10911118. https:/ / doi.org/10.22251/jlcci.2016.16.9.1091

Kitcher, P. (2007). Does 'race' have a future? Philosophy \& Public Affairs, 35, 293-317. https:/ / doi.org/10.1111/j.10884963.2007.00115.x

Ko, Y., Choi, Y., \& Lee, H. (2015). Development of an analytical framework for dialogic argumentation in the context of socioscientific issues: Based on discourse clusters and schemes. Journal of the Korean Association for Science Education, 35(3), 509-521. https:/ / doi.org/10.14697/jkase.2015.35.3.0509

Kurzban, R., Tooby, J., \& Cosmides, L. (2001). Can race be erased? Coalitional computation and social categorization. Proceedings of the National Academy of Sciences USA, 98, 15387-15392. https://doi.org/10.1073/pnas.251541498

Lee, C. W. (2014). The need for new curriculum in clinical genetic education. Korean Medical Education Review, 16(1), 50-54. https:// doi.org/10.17496/kmer.2014.16.1.050

Lee, H., Abd-El-Khalick, F., \& Choi, K. (2006) Korean science teachers' perceptions of the introduction of socioscientific issues into the science curriculum. Canadian Journal of Science, Mathematics and Technology Education, 6(2), 97-117. https:/ / doi.org/10.1080/14926150609556691

Lee, J. I. (2011). A socio-historical study on the creation of the word 'race' as the 15th century race project. Research in Social Studies Education, 18(4), 61-77.

Lewontin, R. C. (1972). The apportionment of human diversity. In T. Dobzhansky, M. K. Hecht, \& W. C. Steere (Eds.), Evolutionary biology (Vol. 6) (pp. 381-398). New York: Springer. https:/ / doi.org/10.1007/978-1-46849063-3_14 
Lin, S. S., \& Kelsey, J. L. (2000). Use of race and ethnicity in epidemiologic research: Concepts, methodological issues, and suggestions for research. Epidemiologic Review, 22(2), 187-202. https:/ / doi.org/10.1093/oxfordjournals.epirev.a018032

Lincoln, Y. S., \& Guba, E. G. (1985). Naturalistic Inquiry. Beverly Hills, CA: Sage Publications, Inc.

Linnaeus, C. (1753). Systema Naturae (1 1 st ed.). Leiden.

Ludwig, D. (2014). Hysteria, race, and phlogiston. A model of ontological elimination in the human sciences. Studies in History and Philosophy of Science Part C: Studies in History and Philosophy of Biological and Biomedical Sciences, 45, 68-77. https:/ / doi.org/10.1016/j.shpsc.2013.10.007

Macfarlane, B., \& Cheng, M. (2008). Communism, universalism and disinterestedness: Re-examining contemporary support among academics for Merton's scientific norms. Journal of Academic Ethics, 6(1), 67-78. https:/ / doi.org/10.1007/s10805-008-9055-y

Mayr, E. (1942). Systematics and the Origin of Species. Columbia University Press, New York.

McCloskey, M., Caramazza, A., \& Green, B. (1980). Curvilinear motion in the absence of external forces: Naive beliefs about the motion of objects. Science, 210, 1139-1141. https:/ / doi.org/10.1126/science.210.4474.1139

McDonald, B. (2013). The reproduction of biological 'race' through physical education textbooks and curriculum. European Physical Education Review, 19(2), 183-198. https:/ / doi.org/10.1177/1356336X13486052

Merton, R. K. (1942). The normative structure of science. In N. Storer (Ed.), The sociology of science: Theoretical and empirical investigations (pp. 267-278). Chicago: The University of Chicago Press.

Montague, A. (1970). The concept of race. London: Cathier Books.

Montoya, M. J. (2011). Making the Mexican diabetic: Race, science, and the genetics of inequality. CA: University of California Press. https:/ / doi.org/10.1525/california/9780520267305.001.0001

Morning, A. (2014). Does genomic challenge the social construction of race? Sociological Theory, 32(3), 189-207. https://doi.org/10.1177/0735275114550881

Morris, S. G. (2011). Preserving the concept of race: A medical expedient, a sociological necessity. Philosophy of Science, 78, 1260-1271. https:/ / doi.org/10.1086/662279

Ormond, K. E., Hudgins, L., Ladd, J. M., Magnus, D. M., Greely, H. T., \& Cho, M. K. (2011). Medical and graduate students' attitudes toward personal genomics. Genetics in Medicine, 13(5), 400-408. https:/ / doi.org/10.1097/GIM.0b013e31820562f6

Paschou, P., Ziv, E., Burchard, E. G., Choudhry, S., Rodriguez-Cintron, W., Mahoney, M. W., \& Drineas, P. (2007). PCA-correlated SNPs for Structure Identification in Worldwide Human Populations. PLoS Genetics, 3(9), 1672-1686. https:// doi.org/10.1371/journal.pgen.0030160

Reiner, M., Slotta, J. D., Chi, M. T. H., \& Resnick, L. B. (2000). Naïve physics reasoning: A commitment to substancebased conceptions. Cognition and Instruction, 18(1), 1-34. https://doi.org/10.1207/S1532690XCI1801_01

Roberts, D. E. (2011). What's wrong with race-based medicine? Genes, drugs, and health disparities. Minnesota Journal of Law, Science \& Technology, 12(1), 1-21.

Root, M. (2003). The use of race in medicine as a proxy for genetic difference. Philosophy of Science, 70, 1173-1183. https:// doi.org/10.1086/377398

Rose, N. (2012). The human science in a biological age. ICS Occasional Paper series, 3(1), 1-24.

Schwartz, R. S. (2001). Racial profiling in medical research. The New England Journal of Medicine, 344, 1392-1393. https:/ / doi.org/10.1056/NEJM200105033441810

Senior, P. A., \& Bhopal, R. (1994). Ethnicity as a variable in epidemiological research. British Medical Journal, 309(6950), 327-330. https:/ / doi.org/10.1136/bmj.309.6950.327

Shiao, J. L., Bode, T., Beyer, A., \& Selvig, D. (2012). The genomic challenge to the social construction of race. Sociological Theory, 30(2), 67-88. https:/ / doi.org/10.1177/0735275112448053

Shim, J. K. (2002). Understanding the routinised inclusion of race, socioeconomic status and sex in epidemiology: The utility of concepts from technoscience studies. Sociology of Health $\mathcal{E}$ Illness, 24(2), 129-150. https:// doi.org/10.1111/1467-9566.00288

Shin, N., Jonassen, H. D., \& McGee, S. (2003). Predictors of well-structured and ill-structured problem solving in an astronomy simulation. Journal of Research in Science Teaching, 40(1), 6-33. https:/ / doi.org/10.1002/tea.10058

Smith, R. (2005). Does reflexivity separate the human sciences from the natural sciences? History of the Human Sciences, 18(4), 1-25. https:/ / doi.org/10.1177/0952695105058468

Son, Y. S. (2010). Bioethics from the standpoint of medicine. Journal of Korean Bioethics Association, 11(2), 77-84. 
Sumner, W. G. (1906). Folkways: A study of the sociological importance of usages, manners, customs, mores, and morals. NY: Mentor.

Templeton, A. R. (2013). Biological races in human. Studies in History and Philosophy of Biological and Biomedical Sciences, 44(3), 262-271. https:/ / doi.org/10.1016/j.shpsc.2013.04.010

Tsodikov, A., Gulati, R., de Carvalho, T. M., Heijnsdijk, E. A. M., Hunter-Merrill, R. A., Mariotto, A. B., de Koning, H. J., \& Etzioni, R. (2017). Is prostate cancer different in black men? Answers from 3 natural history models. Cancer, 123(12), 2312-2319. https:/ / doi.org/10.1002/cncr.30687

UNESCO (1978). Declaration on race and racial prejudice. Retrieved from http:/ / www.unesco.org/webworld/peace_library/UNESCO/HRIGHTS/107-116.HTM

Whitmarsh, I., \& Jones, D. S. (2010). Governance and the uses of race. In What's the use of race? Modern governance and the biology of difference. Cambridge: MIT Press, 1-23.

Winther, R. G., \& Kaplan, J. M. (2013a). Ontologies and politics of bio-genomic 'race.' Theoria: A Journal of Social and Political Theory, 60(3), 54-80.

Winther, R. G., \& Kaplan, J. M. (2013b). The genetic reification of 'race'?: A story of two mathematical methods. Critical Philosophy of Race, 2(2), 204-23.

Wolf, E. (1994). Perilous ideas: Race, culture, people. Current Anthropology, 35, 1-12. https://doi.org/10.1086/204231

Worthman, C. M. (1995). Hormones, sex, and gender. Annual Reviews of Anthropology, 24, 593-617. https:/ / doi.org/10.1146/annurev.an.24.100195.003113

Yoo, H. H., Lee, J. K., \& Shin, S. S. (2017). Explanatory study of medical students' perception of life concept. Korean Medical Education Review, 19(1), 36-46. https:/ / doi.org/10.17496/kmer.2017.19.1.36

Yoon, S. Y., Suh, J. K., \& Park, S. (2014). Korean students' perceptions of scientific practices and understanding of nature of science. International Journal of Science Education, 36(16), 2666-2693. https:/ / doi.org/10.1080/09500693.2014.928834

Youn, S. J., \& Seo, H. A. (2014). Teachers' conceptions about the genetic determinism of human behaviors. Journal of the Korean Association for Science Education, 34(4), 407-415. https:/ / doi.org/10.14697/jkase.2014.34.4.0407

Yudell, M., Roberts, D., DeSalle, R., \& Tishkoff, S. (2016). Taking race out of human genetics. Science, 351(6273), 564565. https:// doi.org/10.1126/science.aac4951

Zeidler, D. L., \& Nichols, B. H. (2009). Socioscientific issues: Theory and practice. Journal of Elementary Science Education, 21(2), 49-58. https:/ / doi.org/10.1007/BF03173684

Zeidler, D. L., Sadler, T. D., Simmons, M. L., \& Howes, E. V. (2005). Beyond STS: A research-based framework for socioscientific issues education. Science Education, 89, 357-377. https://doi.org/10.1002/sce.20048

\section{http://www.ejmste.com}

